\title{
Correction
}

\section{Correction: Teichert et al., Performance Monitoring in Monkey Frontal Eye Field}

In the article "Performance Monitoring in Monkey Frontal Eye Field" by Tobias Teichert, Dian Yu, and Vincent P. Ferrera, which appeared on pages 1657-1671 of the January 29, 2014 issue, the top two of three panels in Figure 2 were accidentally cropped. The corrected Figure 2 is shown below and corrected on the online PDF version.

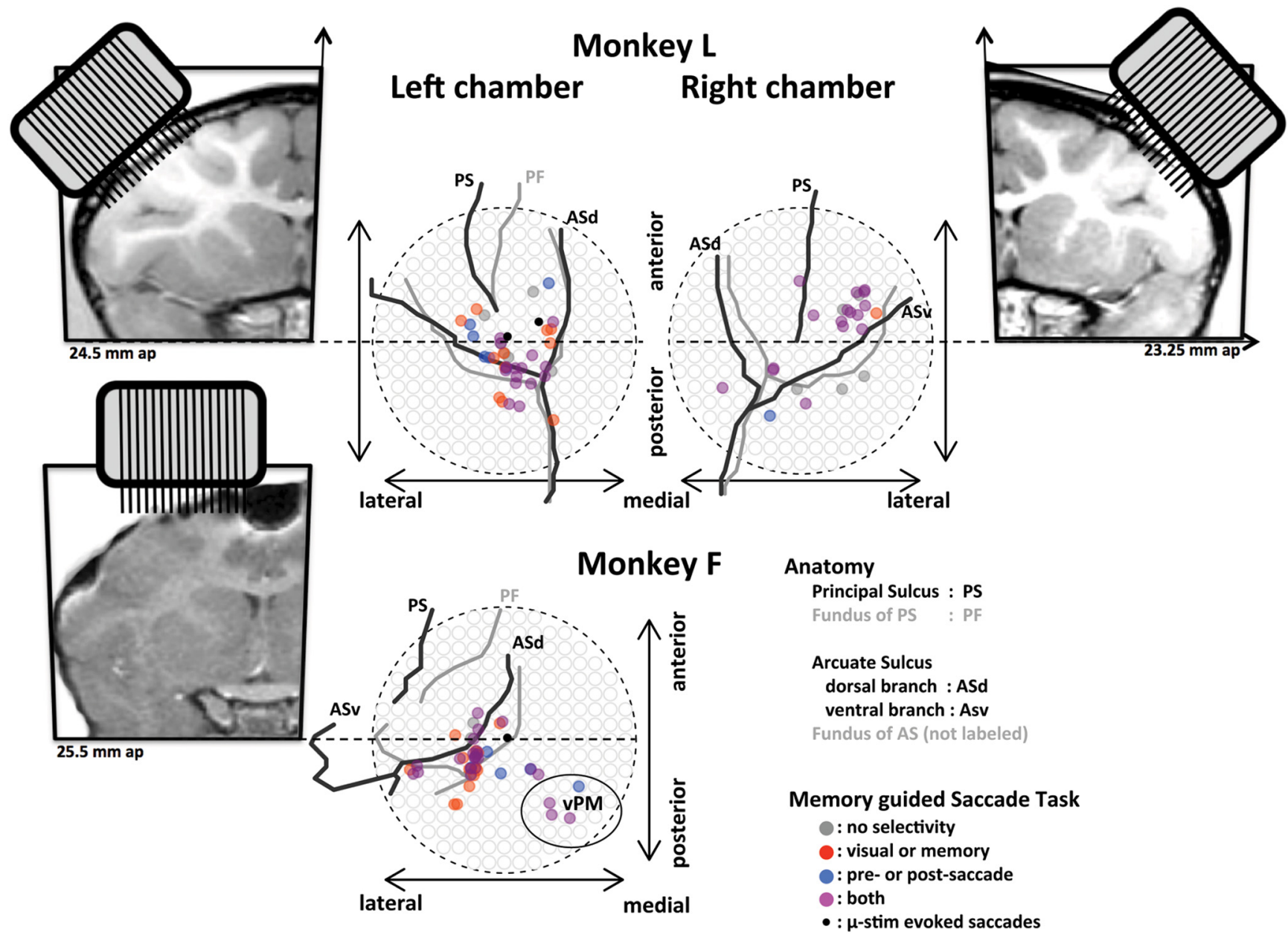

Figure 2. 